\title{
A Fuzzy Inference System Using Gaussian Distribution Curves for Forest Fire Risk Estimation
}

\author{
Lazaros Iliadis ${ }^{1}$, Stergios Skopianos ${ }^{1}$, Stavros Tachos $^{2}$, and Stefanos Spartalis ${ }^{3}$ \\ ${ }^{1}$ Democritus University of Thrace, Pandazidou 193 str., Orestiada, Greece \\ liliadis@fmenr.duth.gr \\ ${ }^{2}$ Aristotle University of Thessaloniki, Department of Informatics \\ ${ }^{3}$ Democritus University of Thrace, Xanthi, Greece
}

\begin{abstract}
This paper describes the development of a fuzzy inference system under the MATLAB platform. The system uses three distinct Gaussian distribution fuzzy membership functions in order to estimate the partial and the overall risk indices due to wild fires in the southern part of Greece. The behavior of each curve has been investigated in order to determine which one fits better for the specific problem and for the specific areas. Regardless the characteristics of each function, the risky areas have been spotted from 1984 till 2007. The results have shown a reliable performance over time and they encourage its wider use in the near future.
\end{abstract}

Keywords. Fuzzy algebra, Gaussian distribution curves, Fuzzy Inference System, wildfire risk.

\section{Introduction}

Every year, forest fires destroy important forest areas, with enormous consequences. The problem of forest fires occurs mainly in the Mediterranean countries, in Australia, in Canada and the United States [6]. Especially in Greece due to the lack of a proper cadastral survey, the problem of forest fires is related to political elections and also to the cycles of drought [9][10]. More detailed analysis on the problem of forest fires in Greece can be found in [14][16][17].

Fuzzy logic systems are quite flexible and they are used for several purposes such as modeling, forecasting and classification [8]. This research effort aims in the development of a fuzzy inference system, that estimates an integrated fuzzy forest fire risk index offering an overall view of the problem. This is achieved by employing three distinct fuzzy membership functions (of the same family) namely the Gaussian, the Sigmoid and the S-shaped one. The application of fuzzy logic enhances the ability to model proper linguistics that are used in the consequent part of the developed rulebased system. The application area concerns the Greek forest departments of Attica and Peloponnesus which are located in the southern part of the country. The whole research has been performed for the period 1984 to 2007 and the estimation of the integrated risk index has been achieved by considering the annual number of forest fire breakouts and the annual burned forest area for each forest department. 


\subsection{Literature Review}

In order for the appropriate authorities to adopt efficient fire prevention and protection measures, the assistance of modern technology is required towards the evaluation of forest fire risk [6][8][13]. Deeming et al [4], developed the national fire danger rating system (NFDRS), which is still used in the USA after some improvements. It is a system that produces the daily ignition component index and also the man caused risk index. There have been many studies in the United States, in Australia, in New Zealand and in Europe for the long term evaluation of fire risk. A system that evaluates daily as well as long term fire danger is EFFIS (European Forest Fire Information System). It has been developed by the Institute for Environmental and Sustainability Land Management which resides in Italy [1]. In reality EFFIS is an attempt towards the creation of a common European indicator for fire danger. In Greece, the lab of forest informatics of the Democritus University of Thrace has developed decision support systems that are employing heuristic reasoning and fuzzy logic (fuzzy expected intervals) in order to estimate wild fire risk for the following year. The heuristic reasoning is based on the effect of political elections and drought cycles (following a periodicity of 3 to 5 years) in the number of forest fires in Greece [7].

\section{Intelligent Information Systems}

\subsection{Fuzzy Algebra}

Fuzzy logic [18],[2],[11], allows the definition of real world concepts, such as "area with high vulnerability to forest fires" in the form of fuzzy sets. Every member of the universe of discourse belongs to a fuzzy set with a different degree of membership, ranging from 0 to 1 . The degree of membership can be estimated by the use of proper membership functions (MF). Fuzzy sets correspond to real life linguistics. Fuzzy logic is an human knowledge embodying tool through operational algorithms [6][11]. In fuzzy algebra there are many kinds of membership functions but the most characteristic are the triangular, the trapezoidal ones and the family of the sigmoid functions. Sigmoid MF have been used in several research efforts in order to develop fuzzy inference systems [3]. This research effort has been implemented by applying three distinct fuzzy functions that all belong to the sigmoid family.

\subsubsection{The Functions of the Gaussian Distribution Curve Family}

The fuzzy toolbox of the Matlab platform has been used in order to obtain the membership degrees for each forest department, given by three MF that belong to the Gaussian distribution curve, namely the Gaussian, the Sigmoid, and the S-shaped one. The Gaussian fuzzy membership function (GFMF) is symmetrical and it depends on two parameters $\mathrm{c}$ and $\sigma$ which represent the center and the width of a fuzzy set [15]. More details can be seen in the following figure 2. Gaussian fuzzy membership functions are quite popular in the fuzzy logic literature, as they are the basis for the connection between fuzzy systems and radial basis function neural networks. A typical form of a GFMF can be seen in the following equation 1 [7]. 


$$
f(x, \sigma, c)=e^{\frac{-(x-c)^{2}}{2 \sigma^{2}}}
$$

The Sigmoid fuzzy membership function (SFMF) is given by the following equation 2 . It is a continuous monotonic mapping of the input into a value between 0.0 and 1.0.

$$
f(x ; a, c)=\frac{1}{1+e^{-a(x-c)}}
$$

In the case of the SFMF the parameters a, c define the schema and the position of the curve [7]. Depending on the sign of the parameter a, it is inherently open to the right or to the left, and thus it is appropriate for representing concepts such as "very large" or "very negative". The S-shaped membership function (SSFMF) is a spline-based curve and it is a special version of the Sigmoid one. The following table 1, presents the commands that were employed in MATLAB in order to perform the membership functions.

Table 1. Fuzzy Membership functions used

\begin{tabular}{|c|c|}
\hline Fuzzy membership function & MATLAB's implementation command \\
\hline GFMF & $y=\operatorname{Gaussmm}(x,[\operatorname{sig} c])$ \\
\hline SFMF & $y=\operatorname{Sigmf}(x,[a c])$ \\
\hline SSFMF & $y=\operatorname{Smf}(x,[a b])$ \\
\hline
\end{tabular}

It should be specified that the parameters a and $b$ locate the extremes of the sloped portion of the curve. The following figure 1 shows the actual shape of the three sigmoid membership function that have been applied.
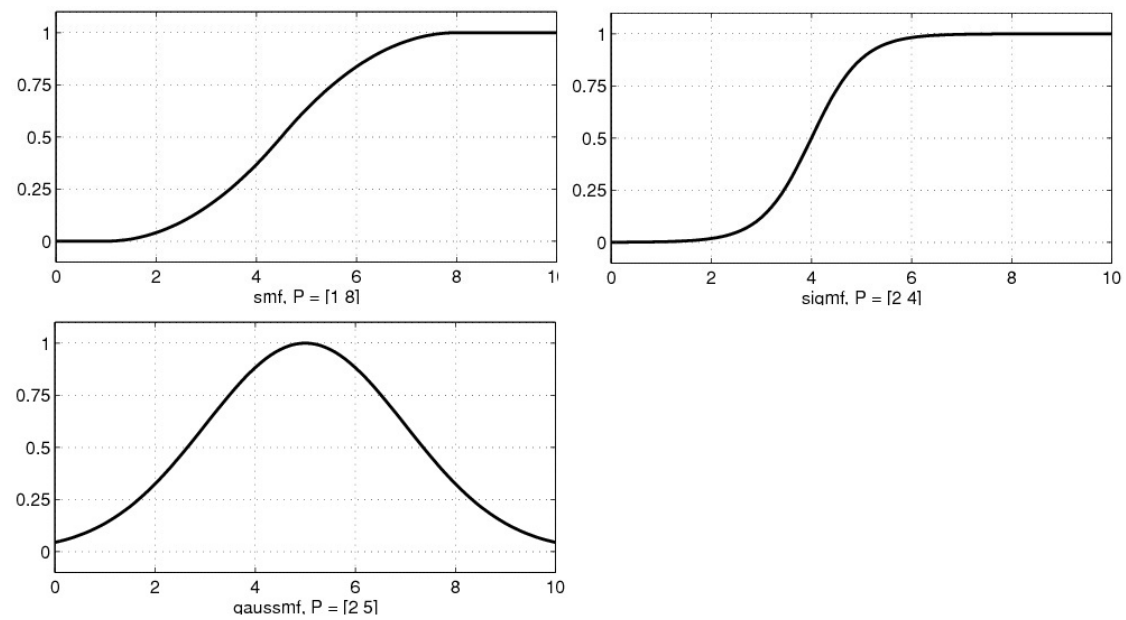

Fig. 1. Graphics of the three employed membership functions 




Fig. 2. The center and the width of a Gaussian membership function

\subsubsection{Fuzzy Aggregation Operators}

According to fuzzy algebra, every element of the universe of discourse can belong to a fuzzy set $\tilde{A}$ and simultaneously to its complement $\tilde{A}_{C}$ with a degree of membership complementary to 1 . T-Norms are the fuzzy conjunction operators between fuzzy sets. Fuzzy algebra contains several $\mathrm{T}$-Norms, each one of them offering a different approach of the fuzzy AND, operation [7],[11]. The following table 2 below contains equations 3 and 4 and it presents a small sample of the most common T-Norms. They have a wide range of applications including the evaluation of Artificial Neural Networks [5].

Table 2. Sample T-Norms

\begin{tabular}{|c|c|}
\hline $\begin{array}{c}\text { T-Norm } \\
\text { name }\end{array}$ & T-Norm equation \\
\hline Min (3) & $\tilde{A} \wedge \tilde{B}=\left\{\left(\begin{array}{cc}\left.\left.x, \mu_{\tilde{\mathrm{A}} \cap \tilde{\mathrm{B}}}(x)\right) \mid \mu_{\tilde{\mathrm{A}} \cap \tilde{\mathrm{B}}}(x)=\mu_{\tilde{\mathrm{A}}}(x)^{\wedge} \mu_{\tilde{\mathrm{B}}}(x)=\min \left(\mu_{\tilde{\mathrm{A}}}(x), \mu_{\tilde{\mathrm{B}}}(x)\right)\right\} \\
\hline \begin{array}{c}\text { Drastic } \\
\text { Product } \\
(4)\end{array} & \tilde{A} \wedge \tilde{B}=\min \left\{\mu_{\tilde{A}}(\mathrm{x}), \mu_{\tilde{B}}(\mathrm{x})\right\} \text { if } \max \left\{\mu_{\tilde{A}}(\mathrm{x}), \mu_{\tilde{B}}(\mathrm{x})\right\}=1 \text { else } \\
\tilde{A} \wedge \tilde{B}=0\end{array}\right.\right.$ \\
\hline
\end{tabular}

The choice of the appropriate norm depends on the perspective under which the problem is examined. For example, if the developer needs an optimistic norm that will assign the least potential overall degree of risk, then the min T-norm should be applied, whereas if the developer wishes to distinguish the cases that are characterized by extreme values for one or more risk parameters, the drastic product is the proper norm to be employed. 


\section{Developing the Fuzzy Inference System}

The risk estimation is based on historical data that refer to the annual forest fire frequency (FFF) and to the annual burned area (ABA) in each area under study. The fuzzy inference system has been developed in the MatlLab integrated environment and more specifically by writing MatLab code in the development environment and also by the use of the fuzzy toolbox for the construction of the fuzzy membership functions and for the Ruleset construction. The primitive data that have been used as input have been initially stored in Microsoft Excel sheets and they are input to the fuzzy inference system by employing commands of the type: $\vec{C}=x$ sread ('data1.xls','1990','B2:B89'); This sample command imports data concerning burned areas for 1990 into a MATLAB vector named C.

Several commands of this type have been written in order to store each column containing the annual FFF and the ABA in proper one dimensional Matrices (vectors). All of these commands have been stored in a MatLab programming file called Input_Data.m. The benefit from the creation of this file is that it runs just by typing the name of the file in the command line. For each one of the two input variables three fuzzy sets have been formed corresponding to proper Linguistics. The following six fuzzy sets have been formed, namely:

$$
\begin{aligned}
& \tilde{A}_{1=}\left\{\left(\vec{X}_{i} \mu_{i}\right) / i=1 . . n . . \text { "low risky due to FFF" }\right\} \\
& \left.\left.\tilde{B}_{1=\left\{\left(X_{i}\right.\right.} \mu_{i}\right) / i=1 . . n . . \text { "risky due to FFF" }\right\} \\
& \tilde{C}_{1=}\left\{\left(\vec{X}_{i} \mu_{i}\right) / i=1 . . n . . \text { "extremely risky due to FFF" }\right\} \\
& \tilde{A}_{2=}\left\{\left(\vec{X}_{i} \mu_{i}\right) / i=1 . . n . . \text { "low risky due to ABA" }\right\} \\
& \tilde{B}_{2=}\left\{\left(\vec{X}_{i} \mu_{i}\right) / i=1 . . n . . " \text { risky due to } \mathrm{ABA} ",\right\} \\
& \tilde{C}_{2=}\left\{\left(\vec{X}_{i} \mu_{i}\right) / i=1 . . n . . \text { "extremely risky due to ABA" }\right\}
\end{aligned}
$$

where $\mathrm{n}$ is the number of case under study. Each forest department belongs to all six fuzzy sets with a distinct degree of membership. Of course the characteristic linguistic that describes a case is the one with the highest degree of membership. This approach not only allows the proper definition of linguistics that show clearly the status of an area due to one factor, but it also enables the distinction between two cases of the same linguistic. For example if two forest departments are both high risky, their degree of membership determines which one is more risky than the other.

During the design of the fuzzy inference system, the developer has to input the maximum and the minimum annual values ever recorded in Greece for the forest fire frequency and for the total burned area. Then the fuzzy toolbox determines the values 
of the $\sigma$ and c parameters of the Gaussian function and the parameter values $\alpha, \mathrm{c}$, used by the Sigmoid and the S-shaped membership functions. For the output of the system also three fuzzy sets corresponding to three linguistics have been defined namely:

$$
\begin{gathered}
\tilde{A}_{3=}\left\{\left(\vec{X}_{i} \mu_{i}\right) / i=1 . . n \text {.. "low risky due to integrated risk" }\right\} \\
\tilde{B}_{3=}\left\{\left(\vec{X}_{i} \mu_{i}\right) / i=1 . . n . \text {."risky due to integrated risk" }\right\} \\
\tilde{C}_{3=}\left\{\left(\vec{X}_{i} \mu_{i}\right) / i=1 . . n . . \text { "extremely risky due to integrated risk" }\right\}
\end{gathered}
$$

After the storage of the data in vectors and the definitions of the fuzzy membership functions the Ruleset has been constructed. Figure 3, presents the design of the Ruleset. Several approaches have been proposed lately in order to design decision tables and decision trees [12]. In this case, due to the small number of parameters a rather

\begin{tabular}{|c|c|c|c|c|c|c|c|c|c|}
\hline $\begin{array}{l}\text { forest fire } \\
\text { frequency }\end{array}$ & LR & $\mathbf{R}$ & LR & $\mathbf{R}$ & ER & $\mathbf{R}$ & ER & ER & LR \\
\hline $\begin{array}{l}\text { annual burned } \\
\text { area }\end{array}$ & LR & $\mathbf{L R}$ & $\mathbf{R}$ & $\mathbf{R}$ & $\mathbf{R}$ & ER & ER & LR & $\mathbf{E R}$ \\
\hline \multicolumn{10}{|l|}{ OUTPUT } \\
\hline & LR & LR & $\mathbf{R}$ & $\mathbf{R}$ & $\mathbf{R}$ & ER & ER & $\mathbf{R}$ & $\mathbf{R}$ \\
\hline
\end{tabular}
heuristic approach has been followed in order to minimize the number of required rules as much as possible and to produce a quite rational system.

Fig. 3. A sample of the Ruleset of the fuzzy inference system

The unification of the partial risk degrees due to the number of forest fire frequencies and to the total burned area to an integrated risk index has been performed by the system by the use of the minimum T-Norm.

Three distinct systems have been developed, each one using a specific sigmoid membership function and they have been saved as a ffriskGaus.fis, ffriskSigm.fis and ffriskSm.fis using the Gaussian, the Sigmoid and the S-shaped membership functions respectively. Each one of the developed fuzzy inference systems can be executed from the Matlab command line by using the commands readfis and evalfis.

For example the commands: fffrisk = readfis('ffriskGaus.fis'); and intergrated_risk = evalfis(ffriskGaus, fffrisk); have been used to execute the Gaussian system and they store the output (unified degrees of membership taking values from 0 to 1) into a proper matrix named integrated_risk. The results have been exported to sheets of Microsoft Excel again by using the MatLab command xlswrite.

\section{Results - Discussion}

The system has been tested and evaluated with actual data related to forest fire incidents in Greece for the period 1984-2007 which is a quite long time interval. 
Table 3. PRI based on the FFF using the Gaussian and $\mathrm{S}$ shaped functions

\begin{tabular}{|c|c|c|c|c|c|c|c|}
\hline Year & $\begin{array}{c}\text { forest } \\
\text { depart- } \\
\text { ment }\end{array}$ & $\begin{array}{c}\text { GFMF } \\
\text { Ex- } \\
\text { tremely } \\
\text { risky } \\
\text { index } \\
\text { FFF }\end{array}$ & $\begin{array}{c}\text { SFMF } \\
\text { Extremely } \\
\text { risky in- } \\
\text { dex FFF }\end{array}$ & Year & $\begin{array}{c}\text { forest } \\
\text { depart- } \\
\text { ment }\end{array}$ & $\begin{array}{c}\text { GFMF } \\
\text { Ex- } \\
\text { tremely } \\
\text { risk } \\
\text { index } \\
\text { FFF }\end{array}$ & $\begin{array}{c}\text { SFMF } \\
\text { Ex- } \\
\text { tremely } \\
\text { risky } \\
\text { index } \\
\text { FFF }\end{array}$ \\
\hline \multirow[t]{3}{*}{1985} & Pyrgos & 0.9737 & 1 & 1999 & Hleia & 1 & 1 \\
\hline & Olympia & 0.9538 & 0.966 & & Messinia & 1 & 1 \\
\hline & Patra & 0.8275 & & & Argolida & 0.9967 & 1 \\
\hline \multirow[t]{4}{*}{1986} & Olympia & 0.9802 & 1 & 2000 & Messinia & 1 & 1 \\
\hline & Pyrgos & 0.995 & 1 & & Korinthos & 1 & 1 \\
\hline & Patra & 0.956 & 0.9938 & & Hleia & 0.9994 & 1 \\
\hline & Korinthos & 0.9231 & 0.9753 & & Lakonia & 0.9508 & 1 \\
\hline \multirow[t]{2}{*}{1987} & Pyrgos & 1 & 1 & 2001 & Messinia & 1 & 1 \\
\hline & Olympia & 0.9692 & 1 & & Korinthos & 1 & 1 \\
\hline \multirow[t]{2}{*}{1988} & Olympia & 0.9523 & 1 & & Arkadia & 1 & 1 \\
\hline & Argolida & 0.9692 & 0.962 & & Lakonia & 0.9569 & 1 \\
\hline \multirow[t]{4}{*}{1989} & Pyrgos & 0.9802 & 1 & 2003 & Messinia & 1 & 1 \\
\hline & Olympia & 0.9802 & 1 & & Hleia & 1 & 1 \\
\hline & Tripolh & 0.9802 & 0.9988 & & Arkadia & 0.9999 & 1 \\
\hline & Patra & 0.956 & 1 & & Korinthos & 0.9928 & 1 \\
\hline \multirow[t]{2}{*}{1990} & Pyrgos & 0.9756 & 1 & 2004 & Messinia & 1 & 1 \\
\hline & Olympia & 0.9756 & 0.9882 & & Hleia & 1 & 1 \\
\hline \multirow[t]{3}{*}{1991} & Argolida & 0.9692 & 0.9644 & & Korinthos & 0.9889 & 0.9828 \\
\hline & Korinthos & 0.9692 & 0.9644 & & Arkadia & 0.9595 & 0.946 \\
\hline & Olympia & 0.9321 & 1 & & Lakonia & 0.9406 & 0.92 \\
\hline \multirow[t]{2}{*}{1992} & Korinthos & 0.9978 & 1 & & Argolida & 0.9231 & 1 \\
\hline & Olympia & 0.9802 & 1 & 2005 & Messinia & 1 & 1 \\
\hline 1993 & Kalamata & 0.9396 & 1 & & Hleia & 1 & 1 \\
\hline \multirow[t]{2}{*}{1994} & Argolida & 0.9287 & 1 & & Korinthos & 0.9996 & 0.9929 \\
\hline & Kalamata & 0.9737 & 0.9444 & 2006 & Hleia & 1 & 1 \\
\hline \multirow[t]{2}{*}{1995} & Kalamata & 1 & 1 & & Messinia & 1 & 1 \\
\hline & Amaliada & 0.9577 & 1 & & Arkadia & 0.9928 & 1 \\
\hline \multirow[t]{4}{*}{1996} & Kalamata & 1 & 1 & & Argolida & 0.9851 & 0.9812 \\
\hline & Pyrgos & 0.96 & 0.933 & 2007 & Hleia & 1 & 1 \\
\hline & Pendeli & & 1 & & Korinthos & 1 & 1 \\
\hline & Parnitha & & 1 & & Patra & 0.96 & 1 \\
\hline
\end{tabular}


Table 3. (continued)

1997 \begin{tabular}{crccrr} 
Kalamata & 1 & 1 & Messinia & 0.9675 & \\
Olympia & 1 & 1 & Arkadia & 0.8 & 1 \\
Pyrgos & 0.9596 & & & & \\
\hline
\end{tabular}

The above Table 3 presents clearly the obtained partial risk indices based on the number of forest fire incidents' frequencies, with the use of both Gaussian an S-shaped membership functions only for the cases of the Extremely risky forest departments.

Table 4. PRI for the ABA and overall risk indices for the combination of GFMF and Min (1985-2007)

\begin{tabular}{|c|c|c|c|c|c|c|c|c|c|}
\hline Year & $\begin{array}{c}\text { Forest } \\
\text { department }\end{array}$ & $\begin{array}{c}\text { GFMF } \\
\text { Ex- } \\
\text { tremely } \\
\text { risky } \\
\text { Partial } \\
\text { index } \\
\text { ABA }\end{array}$ & $\begin{array}{c}\text { SSFMF } \\
\text { Ex- } \\
\text { tremely } \\
\text { risky } \\
\text { Partial } \\
\text { index } \\
\text { ABA }\end{array}$ & $\begin{array}{c}\text { OVER } \\
\text { ALL } \\
\text { risk } \\
\text { inde } \\
\text { GFMF } \\
\text { and } \\
\text { Min } \\
\text { Norm } \\
\end{array}$ & Year & $\begin{array}{c}\text { Forest } \\
\text { depart- } \\
\text { ment }\end{array}$ & $\begin{array}{c}\text { GFMF } \\
\text { Ex- } \\
\text { tremely } \\
\text { risky } \\
\text { Partial } \\
\text { index } \\
\text { ABA }\end{array}$ & $\begin{array}{c}\text { SSFMF } \\
\text { Ex- } \\
\text { tremely } \\
\text { risky } \\
\text { Partial } \\
\text { index } \\
\text { ABA }\end{array}$ & $\begin{array}{c}\text { OVERA } \\
\text { LL risk } \\
\text { index } \\
\text { GFMF } \\
\text { and Min } \\
\text { Norm }\end{array}$ \\
\hline \multirow[t]{3}{*}{1984} & Kapandriti & 1 & 1 & & 1994 & Patra & 1 & 1 & XR 0.181 \\
\hline & Aigaleo & 0.9817 & 1 & & & Pendelh & 1 & 1 & XR 0.606 \\
\hline & Korinthos & 0.9247 & 1 & & & Gytheio & 1 & 1 & R 0.323 \\
\hline \multirow[t]{5}{*}{1985} & Aigaleo & 1 & 1 & $\begin{array}{c}\mathrm{R} 0.150 \\
\mathrm{XR}\end{array}$ & 1995 & Patra & 1 & 1 & R 0.969 \\
\hline & Megara & 1 & 1 & $\begin{array}{l}0.110 \\
\mathrm{XR}\end{array}$ & & Gytheio & 1 & 1 & XR 0.369 \\
\hline & Patra & 0.9999 & 1 & $\begin{array}{l}0.827 \\
\mathrm{XR}\end{array}$ & & $\begin{array}{l}\text { Molaoi } \\
\text { Kalamat }\end{array}$ & 0.9584 & 1 & XR 0.310 \\
\hline & Lavrio & 0.9903 & 1 & $\begin{array}{l}0.582 \\
\mathrm{XR}\end{array}$ & & $\mathrm{a}$ & 0.9525 & 0.9191 & XR 0.952 \\
\hline & Amaliada & 0.9522 & 1 & $\begin{array}{c}0.457 \\
\mathrm{XR}\end{array}$ & 1996 & Molaoi & 1 & 1 & XR 0.230 \\
\hline \multirow[t]{4}{*}{1986} & Korinthos & 1 & 1 & 0.923 & & $\begin{array}{l}\text { Patra } \\
\text { Korin- }\end{array}$ & 0.9718 & 1 & XR 0.234 \\
\hline & Molaoi & 0.9867 & 1 & $\begin{array}{c}\text { R } 0.946 \\
\text { XR }\end{array}$ & & thos & 0.9969 & 0.9904 & XR 0.774 \\
\hline & Olymbia & 0.9356 & 0.9249 & $\begin{array}{l}0.935 \\
\text { XR }\end{array}$ & 1997 & Olympia & 1 & 1 & XR 1 \\
\hline & Pyrgos & 0.9097 & 0.8943 & $\begin{array}{c}0.909 \\
\text { XR }\end{array}$ & & $\begin{array}{l}\text { Gytheio } \\
\text { Korin- }\end{array}$ & 0.9886 & 1 & R 0.946 \\
\hline \multirow[t]{3}{*}{1987} & Patra & 1 & 1 & $\begin{array}{c}0.681 \\
\text { XR }\end{array}$ & 1998 & thos & 1 & 1 & XR 0.700 \\
\hline & Kalamata & 0.9868 & 1 & $\begin{array}{c}0.754 \\
\text { XR }\end{array}$ & & $\begin{array}{l}\text { Pendeli } \\
\text { Kapan- }\end{array}$ & 1 & 1 & XR 0.290 \\
\hline & Moaloi & 1 & 1 & 0.457 & & driti & 0.95 & 1 & R 0.950 \\
\hline
\end{tabular}


Table 4. (continued)

\begin{tabular}{|c|c|c|c|c|c|c|c|c|c|}
\hline & Argolida & 0.9712 & 0.9675 & $\begin{array}{c}\mathrm{XR} \\
0.339\end{array}$ & 1999 & Lakonia & 1 & 1 & XR 0.910 \\
\hline \multirow[t]{2}{*}{1988} & Kalamata & 1 & 1 & R 0.216 & & Messhnia & 0.9679 & 1 & XR 0.967 \\
\hline & Tripolh & 0.9024 & 1 & 0.153 & & Argolida & 0.9998 & 1 & XR 0.996 \\
\hline \multirow[t]{4}{*}{1989} & Pyrgos & 1 & 1 & $\begin{array}{c}\text { XR } \\
0.980 \\
\text { XR }\end{array}$ & 2000 & $\begin{array}{l}\text { Korin- } \\
\text { thos } \\
\text { Xyloka- }\end{array}$ & 1 & 1 & XR 1 \\
\hline & Xylokastro & 0.9201 & 1 & $\begin{array}{l}0.920 \\
\text { XR }\end{array}$ & & tsro & 1 & 1 & XR 0.433 \\
\hline & Patra & 1 & 1 & $\begin{array}{c}0.956 \\
\mathrm{XR}\end{array}$ & & $\begin{array}{l}\text { Arkadia } \\
\text { Kapan- }\end{array}$ & 0.8479 & 1 & XR 0.847 \\
\hline & Sparti & 0.9978 & 0.9835 & $\begin{array}{c}0.882 \\
\text { XR }\end{array}$ & 2001 & driti & 1 & 1 & XR 0.244 \\
\hline \multirow[t]{3}{*}{1990} & Kapandriti & 1 & 1 & 0.657 & & Lakonia & 1 & 1 & XR 0.965 \\
\hline & Korinthos & 1 & 1 & $\begin{array}{c}\text { R } 0.324 \\
\text { XR }\end{array}$ & & Arkadia & 0.9708 & 1 & XR 0.970 \\
\hline & Molaoi & 0.9737 & 1 & $\begin{array}{c}0.673 \\
\text { XR }\end{array}$ & 2003 & Arkadia & 1 & 1 & XR 0.999 \\
\hline \multirow[t]{4}{*}{1991} & Kapandriti & 1 & 1 & $\begin{array}{c}0.135 \\
\text { XR }\end{array}$ & & Hleia & 1 & 1 & XR 1 \\
\hline & Korinthos & 0.8667 & 1 & $\begin{array}{c}0.866 \\
\text { XR }\end{array}$ & & Argolida & 0.9166 & 1 & XR 0.928 \\
\hline & Argolida & 0.9704 & 1 & $\begin{array}{c}0.969 \\
\text { XR }\end{array}$ & 2004 & Lakonia & 1 & 1 & XR 0.940 \\
\hline & Olympia & 0.9584 & 0.9349 & $\begin{array}{c}0.932 \\
\text { XR }\end{array}$ & & Lavrio & 1 & 1 & XR 0.740 \\
\hline \multirow[t]{6}{*}{1992} & Pendeli & 1 & 1 & $\begin{array}{c}0.766 \\
\mathrm{R}\end{array}$ & & Hleia & 0.9136 & 1 & XR 0.913 \\
\hline & Kapandriti & 1 & 1 & $\begin{array}{c}0.1543 \\
\mathrm{R}\end{array}$ & 2005 & Pendeli & 1 & 1 & $\begin{array}{c}\text { XR } 0.432 \\
\text { XR }\end{array}$ \\
\hline & Sparti & 0.9065 & 1 & $\begin{array}{c}0.2226 \\
\text { XR }\end{array}$ & & Lakonia & 1 & 1 & 0.8795 \\
\hline & Lavrio & 0.9794 & 1 & $\begin{array}{c}0.657 \\
\mathrm{XR}\end{array}$ & & Messhnia & 0.9393 & 1 & XR 0.939 \\
\hline & Kalamata & 0.9850 & 0.9771 & $\begin{array}{c}0.882 \\
\text { XR }\end{array}$ & & Arkadia & 0.9761 & 1 & XR 0.841 \\
\hline & Argolida & 0.9845 & 0.9764 & $\begin{array}{c}0.748 \\
\text { XR }\end{array}$ & 2006 & $\begin{array}{l}\text { Lakonia } \\
\text { Xyloka- }\end{array}$ & 1 & 1 & XR 0.718 \\
\hline \multirow[t]{4}{*}{1993} & Kalamata & 1 & 1 & 0.939 & & tsro & 0.8276 & 1 & XR 0.102 \\
\hline & Tripolh & 1 & 1 & $\begin{array}{c}\text { R } 0.923 \\
\text { XR }\end{array}$ & & Arkadia & 0.9874 & 0.9892 & XR 0.992 \\
\hline & Molaoi & 0.8604 & 1 & $\begin{array}{c}0.439 \\
\text { XR }\end{array}$ & 2007 & Hleia & 1 & 1 & XR 1 \\
\hline & Xylokastro & 0.9258 & 1 & 0.354 & & $\begin{array}{l}\text { Arkadia } \\
\text { Korin- } \\
\text { thos }\end{array}$ & $\begin{array}{c}1 \\
0.9337\end{array}$ & 1 & $\begin{array}{l}\text { XR } 0.798 \\
\text { XR } 0.933\end{array}$ \\
\hline
\end{tabular}


The determination of the most risky areas based on partial risk indices (due to forest fire frequencies or due to the annual burned area) is similar regardless the use of the Gaussian, the Sigmoid or the S-shaped membership functions. However the Sshaped function assigns the highest risk value more often whereas the Gaussian one differentiates the forest departments more clearly by assigning them with a wide range of risk indices.

Table 4 presents the partial risk indices for the extremely risky areas according to the annual burned area, in the cases of the Gaussian and of the S-shaped membership functions. The estimated overall risk indices' vector (obtained as the output of the fuzzy inference system) for the Gaussian membership function and for the Min TNorm is also presented clearly in the above Table 4. It contains the most risky forest departments based on partial risk indices and also on the overall risk index (considering risk due to both FFF and ABA). It estimates their corresponding linguistics (risky $\mathrm{R}$, or extremely risky XR) only for the Gaussian function due to the fact that it offers a more rational production of risk indices, whereas the other two functions assign the highest index with the value 1 for too many cases and thus there is no proper distinction between the cases. The determination of the unified overall risk indices has been performed by the fuzzy inference system based on the Ruleset which is presented in figure 3 .

\section{Conclusions}

The annual 'extremely risky' PRIs and the overall integrated 'extremely risky' indices obtained by the system for each year were compared to the actually most risky areas based on the number of FFF and on the ABA for the following year in order to determine the validity of the system. As far as the Gaussmf curve is concerned, for the parameter FFF the percentages of successful risk characterization reaches as high as $70 \%$. The same function for the parameter of the annual burned area offers a percentage of success equal to $48 \%$. The Sigmoid function (Sigmf), for the parameter FFF has also a percentage of successful risk characterizations as high as $70 \%$, but for the burned area the percentage is $51 \%$. Finally Smf has a percentage of success as high as $74 \%$ for the number of forest fires and $46 \%$ for the burned area. During the period 1985-2007 the overall integrated risk index obtained by employing the min T-Norm offers an average accuracy of $65 \%, 54 \%$ and $52 \%$ for the cases of the Gaussian, Sigmoid and S-shaped membership functions respectively. The Gaussian function achieves the highest percentages of success towards overall risk estimation, whereas the other two functions give also satisfying results. The system will be extended by applying weights in the unification of the risk indices according to the importance of each factor.

\section{References}

1. Ayanz, J.S.M., Barbosa, P.M., Schmuck, G., Liberta, G.: The European Forest Fire Information System (EFFIS), European Commission. JIR Institute for Environment and sustainability (2003), http://natural-hazards.jrc.it/documents/fires/ 2003-publications / EFFIS-earsel-paper.pdf 
2. Cox, E.: Fuzzy Modeling and Genetic Algorithms for Data Mining and Exploration. Elsevier Inc., USA (2005)

3. Duprey, B., Taheri, S.: A Fuzzy Based Stability Index Using a Right Sigmoid Membership Function SAE. International Journal of Commercial Vehicles 2(2) (March 2010)

4. Deeming, J., Burgan, R., Cohen, J.: The National Fire Danger Rating System USDA (1978)

5. Iliadis, L., Spartalis, S., Tachos, S.: Application of fuzzy T-norms towards Artificial Neural Networks evaluation: A case from wood industry. Journal Information Sciences, Informatics and Computer Science Intelligent Systems Applications 178(20), 3828-3839 (2008)

6. Iliadis, L.: A decision support system applying an integrated Fuzzy model for long - term forest fire risk estimation. Environmental Modeling and Software 20(5), 613-621 (2005)

7. Iliadis, L.: Intelligent Information Systems in Risk Estimation Stamoulis Editors (2007) (Greek)

8. Iliadis, L., Papastavrou, A., Lefakis, P.: A computer-system that classifies the prefectures of Greece in forest fire risk zones using fuzzy sets. Journal Forest policy and Economics 4(1), 43-54 (2002)

9. Kailidis, D.: Forest fires, 3rd edn., Giahoudi-Giapouli editions. Thessaloniki, Greece, 510 p. (1990) (in Greek)

10. Kailidis, D., Xanthopoulos, G.: The forest fire problem in Greece. Aristotelian University of Thessaloniki, Greece, Department of Forestry and Natural Environment, Forest Protection Laboratory. No. 310 (1991)

11. Kecman, V.: Learning and Soft Computing. MIT Press, Cambridge (2001)

12. Kuncheva, L.I., Rodriguez, J.J.: An experimental study on Rotation Forest ensembles. In: Haindl, M., Kittler, J., Roli, F. (eds.) MCS 2007. LNCS, vol. 4472, pp. 459-468. Springer, Heidelberg (2007)

13. Lin, C.: The Development, Systems, and Evaluation of Forest Fire Danger Rating: A Review. Taiwan Forestry Research Institute (2002),

http://fire.tfri.gov.tw/DocRefl4.pdf

14. Markalas, S., Pantelis, D.: Forest fires in Greece in 1993 Aristotelian Univ. of Thessaloniki, Department of Forestry and the Natural Environment, Forest Protection Laboratory. No. 3, 40 p. (1996) (in Greek)

15. Pieczynski, A., Obuchowicz, A.: Application of the General Gaussian Membership Function for the Fuzzy Model Parameters Tunning. In: Rutkowski, L., Siekmann, J.H., Tadeusiewicz, R., Zadeh, L.A. (eds.) ICAISC 2004. LNCS (LNAI), vol. 3070, pp. 350-355. Springer, Heidelberg (2004)

16. Xanthopoulos, G.: Greek forest fires and property damage: A brief history. In: Proceedings - Symposium and Workshop on Protecting People and Homes from Wildfire in the Interior West, October 6-8, Missoula, Montana, USA. USDA For. Serv. Gen. Tech. Rep. INT-251, pp. 199-200, 213 (1988)

17. Xanthopoulos, G.: Forest fires in Greece: Past, present and future. Epikentra (Foundation for Political Research and Advanced Education) 6, 62-71 (1998) (in Greek); Special issue titled "Greek forests: myths and reality - Proposals for the present and for the future

18. Zadeh, L.A.: Inform Control, vol. 12, pp. 94-102 (1968) 